Characterizing variability in state-level regulations governing opioid treatment programs, Journal of Substance Abuse Treatment, Volume 115, 2020, 108008, Joanna R. Jackson, Christopher A. Harle, Ross D. Silverman, Kosali Simon, Nir Menachemi

ISSN 0740-5472, https://doi.org/10.1016/j.jsat.2020.108008

\begin{abstract}
Introduction: The opioid use crisis has left nearly 1 million people in need of treatment. States have focused primarily on policies aimed at decreasing the prevalence of opioid use disorder. However, opioid treatment programs (OTPs), an evidence-based modality which can prevent and decrease opioid-related mortality and morbidity, remain highly complex with variation in treatment by state. A focus on evidence-based state-level regulation of OTPs may help improve the unmet need for treatment. This study characterized the variability in state laws that regulate OTPs and examines how this variability is associated with state characteristics. These data provides an opportunity for policymakers to consider regulations that increase access to care and retention in OTPs, which could improve population health.

Materials and Methods: Utilizing legal mapping techniques, we identified all regulations governing OTPs in effect on January 1, 2017 and determined whether the most common regulations were consistent with best practices. We then examined how the number and type of regulations were associated with state characteristics. All legal mapping research was conducted between November 2017 and March 2019.

Results: We identified 89 different regulations, the most common of which exists in fewer than half of all states; and most exist in less than $25 \%$ of states. Eighteen of the 30 most common regulations were inconsistent with best practice recommendations. Overall, variability in the number and type of OTP regulations was related to geographic location as opposed to state size or political leanings.

Conclusions: Wide-ranging variability in the regulations of OTPs exists across the U.S. The majority of state OTP regulations are not congruent with best practices.
\end{abstract}

Keywords: opioid treatment programs; OTPs; medication-assisted treatment; state regulations, legal mapping; substance use disorder 


\section{Characterizing Variability in State-level Regulations Governing Opioid Treatment Programs}

\section{Introduction}

The U.S. is currently experiencing a crisis with nearly 2.1 million people suffering from opioid use disorder (OUD) of whom over 300,000 receive care from 1,500 opioid treatment programs (OTPs) (Wickersham \& Basey, 2016; Substance Abuse and Mental Health Services Administration [SAMHSA], 2015; SAMHSA, 2016). However, when comparing treatment capacity of medications for opioid use disorder (MOUD) and patient need, over 1 million people remain in need of services (Jones, Campopiano, Baldwin, \& McCance-Katz, 2015). Recently, states have attempted to address the opioid epidemic by focusing on policies aimed at decreasing the prevalence of OUD such as a reduction in opioid prescribing and decreased production of opioids (SAMHSA, 2015b; Kertesz, 2017). Previous attempts to address the opioid epidemic through policy are not believed to be sufficient in order to improve the situation (Kertesz, 2017). A focus on evidence-based state regulation of OTPs which improves the wellbeing of individuals with OUD may be a solution to decrease illicit opioid use and may help meet the needs of those experiencing use disorder.

Facilities that use medications to treat individuals with OUD have been subject to varying degrees of regulation at the federal level since the inception of "opioid maintenance programs" and "dispensaries" in the early 1900's (Peters, 1983). The 1914 Harrison Narcotic Act restricted the use of opiates, subsequently prohibiting medication-assisted treatment (MAT) however by the early 1970s, regulatory reform and political pressures eased lifting the prohibition of MAT and modern-day OTPs emerged("The Comprehensive Drug Abuse Prevention and Control Act ", 1970; "Narcotic Addict Treatment Act ", 1974). Currently, OTPs are regulated by the U.S. Food 
and Drug Administration (FDA), enforced by the Drug Enforcement Administration (DEA), while standards and certification for treatment are created by the Substance Abuse and Mental Health Services Administration (SAMHSA) (Joseph, Stancliff, \& Langrod, 2000) \& Center for Substance Abuse Treatment [CSAT], 2005). In addition, various state and local regulations govern facility operations, clinical care, and staffing in OTPs (Joseph et al., 2000; "Title 42 of the Code of Federal Regulations Part 8," 2001). Due to the multi-layered oversight causing complexity, OTP regulations has been referred to as a "regulatory fog" (Wickersham \& Basey, 2016).

OTPs provide comprehensive care for individuals experiencing OUD including counseling, medical assessments, and MAT (CSAT, 2005). OTP providers primarily utilize methadone, a synthetic opioid ${ }^{15}$ to eliminate or decrease the use of opioids (Goldstein \& Herrera, 1995; Mattick, Breen, Kimber, \& Davoli, 2009), reduce associated mortality (Gibson et al., 2008; Grönbladh, Öhlund, \& Gunne, 1990; Langendam, Van Brussel, Coutinho, \& Van Ameijden, 2001), criminality (Dole, Nyswander, \& Warner, 1968; Farrell et al., 1994), and allow patients to improve their physical, mental and social wellbeing (Joseph et al., 2000; Sun et al., 2015). Previous research has demonstrated, a relationship between state policy requirements and OTP activities (Chriqui, Terry-McElrath, McBride, \& Eidson, 2008; Chriqui, Terry-McElrath, McBride, Eidson, \& VanderWaal, 2007). Researchers believe state policy environments are important determinants in the effectiveness of services offered to those in need (Miller \& Moulton, 2013), and this may in turn explain current variation in treatment and health outcomes across states. To date, however, research on the association of state-level OTP regulation and health outcomes are limited due to the empirical challenges and impracticality of measuring the variability of regulations and amount of regulating bodies (Wickersham \& Basey, 2016). 
The purpose of this paper is to characterize the variability in state laws that regulate

OTPs and examine how this variability is associated with state characteristics such as geographic region, population size, and the political leanings of states' population. As political factors have played a role in the regulation of OTPs (Berridge, 2009; Kuehn, 2005), we are interested in examining if political leanings are related to current policies. We are interested in identifying the most common regulations and characterizing the extent to which these regulations are evidencebased and consistent with recommendations by SAMHSA. Having an accurate representation of variability in these laws will allow future research to better examine the impact of these regulations on opioid-related health outcomes. Moreover, having the current analysis of the regulations will be useful to state policymakers, OTP administrators, and others who need to better understand state regulations, and might be considering policy options.

\section{Materials and Methods}

This study utilizes standard public health law research and mapping methods (Anderson, Tremper, Thomas, \& Wagenaar, 2012; Burris et al., 2010) to systematically code each OTP regulation in the 50 states and the District of Columbia (D.C.), hereinafter referred to as "states" or "state-level", in effect on January 1, 2017. All legal mapping research was conducted between November 2017 and March 2019. Laws for inclusion were identified using keyword searches (e.g. opioid treatment programs, narcotic treatment, methadone) on Westlaw, Justia, and state legislative websites. Additionally, publicly available lists of OTP regulations published by the Prescription Drug Abuse Policy System (Prescription Drug Abuse Policy System [PDAPS], 2018), were used to assure all relevant laws were identified in our keyword searches. A single researcher first extracted and coded all laws; and a second researcher coded a random subset of 
states to assure consistency in coding. No cases were identified where separate researchers coded laws differently. The institutional review board at our university deemed this study as not human subject's research.

The main dependent variables were a series of indicators measuring the presence or absence of different elements of OTP regulation that occur in any state. OTP regulations were defined as those that govern organizations, consistent with SAMHSA's definition of OTPs (SAMHSA, 2015b; "Title 42 of the Code of Federal Regulations Part 8," 2001), administering and dispensing medication assisted treatment for the treatment of OUD (SAMHSA, 2015b). Therefore, per the federal definition, facilities, such as physician office-based practices, that only prescribe buprenorphine and substance use facilities who are not certified by SAMHSA as an OTP are excluded from the definition.

Individual state laws were analyzed and coded into a database such that the entire landscape of OTP regulations were captured. Per standard protocols (Burris, 2018; Wagenaar \& Burris, 2014), information was extracted from an initial group of ten states so emerging themes could be established — and then these states were recoded for consistency. This process was repeated with 10 additional states at a time until no new themes or elements were identified. In cases where no applicable regulations were found, state OTP governing bodies were contacted to obtain further information or to validate the absence of regulations. Stateregulations that were identical to federal laws were coded as not having any unique regulations.

Each binary variable measuring the presence of a given regulation was categorized as pertaining to one of the following six categories: regulations pertaining to medical service delivery (e.g., required testing for tuberculosis), facility operating requirements (e.g., regulations of hours of operation, locations restrictions), administrative requirements (e.g., required quality 
improvement plans), staffing requirements (e.g., required use of certain advanced practice professions), social services related regulations (e.g., requirements for patient discharge or aftercare plan), and physical facility management provisions (e.g., requirements of facility cleanliness). These categories emerged during the open coding process. Two members of the research team met regularly to build consensus around the emerging categories. Lastly, for the five most common regulations in each of the six categories (for a total of 30), we classified each item as a 'best practice' (or otherwise) based upon SAMHSA's list of best practices (SAMHSA, 2015, CSAT, 2005, \& "Title 42 of the Code of Federal Regulations Part 8," 2001) and/or the presence of published literature supporting these practices.

To examine how OTP regulations are associated with state characteristics, we merged in variables including 2017 state population estimates, regions as defined by the US Census Bureau, and the proportion of each state that voted for the Democratic and Republican candidates, respectively, in the 2016 presidential election. States were categorized according to natural cut off-points into small (less than 2 million people), medium, and large (more than 9 million people) groups based on population size. The political leanings of states were categorized by the proportion of the population that voted for the Republican or Democratic candidate in the 2016 presidential election which was obtained from the Federal Election Commission (Federal Elections Commission, 2016). Specifically, we created three categories as follows: (1) states where $55 \%$ or greater voted for the Republican candidate, (2) states where $55 \%$ or greater voted for the Democratic candidate, and (3) states where neither the Democratic candidate nor the Republican candidate received at least $55 \%$ of the populous vote.

\subsection{Statistical Analysis}


To analyze our data, we began by examining the frequency of each type of regulation across the states and D.C. We then created summated scales that were calculated as the total number of individual regulations within each category of OTP regulations. For example, given we identified 26 individual types of regulations in the Medical Services Delivery category, our summated scale for this category could range from 0 to 26 representing the number of unique regulations a given state possessed. We calculated a summated scale for each of the 6 categories and one overall scale that represented a count of all OTP regulations a given state possessed. The summated scales ultimately allowed us to quantify the number of regulations that govern OTPs in a given state within each category and overall.

Next, we examined the relationship between the summated scales and the above state characteristics using analyses of variance (ANOVA). All statistical analyses were conducted using SPSS version 25 and statistical significance was assessed at the $P<0.05$ level.

\section{Results}

As of January 1st, 2017, 47 states had specific regulations governing the operation of OTPs (KS, MT, and WY did not). Two states (ID, NE) regulations were redundant with federal guidelines. In total, 89 individual regulations were identified of which 26 were categorized as pertaining to medical services delivery, 6 pertained to facility operating requirements, 15 pertained to administrative requirements, 19 pertained to staffing requirements, 8 to social services related regulations, and 15 to physical facility management provisions.

The frequency in which each of the individual regulations were found appears in Table 1. Briefly, 42 (82.4\%) of states had at least one OTP regulation governing medical services delivery which was the most common category of regulation. The next most common regulations were those affecting administrative requirements 41 (80.4\%), followed by staffing requirements 40 
(78.4\%), facility operating requirements 37 (72.5\%), social services 28 (54.9\%), and physical facility management requirements $28(54.9 \%)$. The map in figure 1 provides a visual display that identifies the frequency of the 89 regulations in each state.

Table 2 presents information on whether each of the top 5 most frequent regulations in each category was recommended by SAMHSA and/or deemed a best practice. The map in figure 2 provides a visual display of the frequency of common regulations which are best practices in each state. Among the Medical Services Delivery Requirements, only 1 of the 5 most common regulations, specifically, the requirement OTPs ensure humane dosage withdrawal schedules, was considered a best practice by SAMHSA. Among the Administrative Requirements, 3 out of the 5 most common regulations were considered a best practice including requiring a facility quality improvement plan, requiring OTPs to have a patient grievance policy, and requiring OTPs to have a community relations committee. Among the Staffing Requirements, 2 of the 5 most common regulations were considered best practices including the employment of advanced practice professionals, and utilization of a clinical supervisor. Among the Facility Operating Requirements, only 1 of the 5 most common regulations, specifically, restrictions on the hours of operation were consistent with best practices.

Among the Social Services Related regulations, 4 of the 5 most common laws were consistent with best practices including requiring patient discharge or aftercare plans, integration of patient's family into treatment and goals, requirements to provide crisis stabilization services, and requirement the provision of parenting skills in patient education activities. Lastly, among the Physical Facility Management requirements, 1 out of the 5 most common elements were consistent with best practices; specifically, OTP requirements on facility cleanliness. However, within the Physical Facility Management category, requirements on 
facility signage was present in the regulations of 10 states with much variability in language. Specifically, in addition to signage consistent with best practice recommendations, D.C. also requires "metric-apothecaries weight and conversion measure charts" to be posted within the facility ("Title 22-A 6237 DCR 012056", 2015) which are not included in the SAMHSA guidelines.

Table 3 presents information on the mean number of OTP regulations, by category and overall, and how these summated scales are related to state characteristics. When examining U.S. Census regions, several differences were noted. First, states in the West region (average of 7.2 regulations) had significantly fewer OTP regulations in total than states in the Northeast (average of 18.8), Midwest (average of 11.3), or South (21.8) $\mathrm{p}<0.001$. Notably, states in the South had significantly more regulations in the categories of Administrative Requirements, Staffing Requirements, Facility Operating Requirements, and Social Services categories (all $\mathrm{P}$ 's $<0.05$ ); while states in the West had significantly fewer regulations in these categories. Lastly, no differences in the mean number of OTP regulations was observed by population size or the political leanings of states.

\section{Discussion}

Our study is the first to quantify the entire landscape of state OTP regulations that have previously been described as a "regulatory fog" (Wickersham \& Basey, 2016). Supplementing the extensive federal regulations, our study identified 89 different individual regulations that currently exist among states. Importantly, we observed much variability in both the types and the frequency of these regulations. For example, even the most common individual regulations (e.g., required testing for tuberculosis, required patient discharge plans) only exist in fewer than half of states; and most regulations exist in less than a quarter of states. States have long been 
considered a laboratory to examine the effects of different policies which allows successful laws to be replicated by other willing states (Savino, 2009). However, in the case of OTPs, we observe much variation in enacted regulations without the historical ability to determine which laws have improved population health.

We found the majority (18 out of 30 ) of the most common regulations overall, and specifically the most common regulations in the Medical Services Delivery, Staffing, Facility Operations, and Physical Facility Management categories, were not considered best practices by SAMHSA and the literature. This raises the question regarding whether the extent of unsupported state policies might make it more challenging to address the current OUD epidemic and the almost 1 million individuals currently in need of services (Jones et al., 2015). For example, within the Medical Service Delivery category, the most common regulation was required testing for tuberculosis; and this was not classified as a best practice. Notably, individuals with OUD are not typically considered high risk populations who require regular screening (Centers for Disease Control and Prevention [CDC], 1990). Furthermore, the Centers for Disease Control and Prevention (CDC) recommends that providers use tuberculin skintesting only if the evaluation and a course of prescribed therapy can be initiated and completed, which is usually not within the scope of practice for OTPs (CDC, 1990). Thus, the increased cost of any unnecessary screenings adds to the overall costs of treatment which may contribute to decreased access and resources. Tuberculosis screenings contrast with screenings for hepatitis $\mathrm{C}$ and HIV (which are largely not required by most states) and are considered a best practice because those seeking care in OTPS are at elevated risk (Frimpong, 2013; Frimpong, D’Aunno, \& Jiang, 2014). 
Similarly, SAMHSA explicitly discouraged the use of certain regulations that restrict unsupervised dosing of methadone by patients outside of the clinic. Nevertheless, many states have such regulations in effect. SAMHSA acknowledges that being able to utilize take-home medication is of critical importance for patients and impacts their ability and desire to enter and remain in treatment; and federal regulations permit one take-home dose per week in the first 90 days (CSAT, 2005). In our study, we found 12 states (23.5\%) that do not allow any take-home medications during the first 30 days and 7 additional states (13.7\%) that do not allow any during the first 90 days. Medication diversion is often cited as justification for these restrictions, however it has been noted that methadone is not often diverted, especially to individuals for recreational use; and when it is diverted it is often to individuals with OUD who lack access to treatment (National Institutes of Health [NIH], 2007).

The most common regulations in the Social Services category (4 out of 5) and the Administrative requirements category ( 3 out of 5) were supported by evidence and thus endorsed by SAMHSA. As such, there appears to be some variability, by regulation-category, in the implementation of best practice regulations. More research is needed to determine if best practice policies result in improved health outcomes; and whether regulations without supporting evidence result in poorer health outcomes across states.

Importantly, we found variability in both the number and type of OTP regulations was related to geographic location as opposed to state size or political leanings. The states in the West had the fewest number of OTP regulations overall, and by each of the categories observed. On the other hand, the Southern region of the US consistently had the highest number of regulations in each of the categories and overall. This might be related to documented higher rates of OUD and lower than average treatment administration in the South (Abraham, Andrews, 
Yingling, \& Shannon, 2018). Further, given a high proportion of Black residents in the South, the observed higher frequency of certain regulations, particularly those not considered best practices, could contribute to documented racial disparities in access to OUD treatment described in the South (NIH, 2007; Abraham et al., 2018; Napoli et al., 2017). Examining these relationships are important for future research.

Previous researchers have suggested that political leaning may play a role in OTP policies (Berridge, 2009; Kuehn, 2005). Our study failed to find evidence for this assertion. Generally, we found that the overall number of regulations did not differ with respect to states considered Republican, Democratic, or swing based on voting records from the most recent presidential election. However, given the historical context in which OTP have been regulated, more research is warranted to determine the extent to which public opinion, race, or socioeconomic status explain the variation in state regulations given that current political leaning do not appear to do so. The opioid crisis represents a bipartisan opportunity for policymakers to consider regulations that increase access to proven OTP treatment which may then result in overall improvement to population health.

Our study findings must be understood in the context of some limitations. First, we examined and coded OTP regulations as they are written and did not account for varying levels of enforcement and interpretation. We recognize that actual practice may vary from the regulations as they are written. Further, our study focused on state regulation; and we recognize that county-level regulations and state-level professional practice boards could exist that influence OTPs. We did not examine regulations which govern all MOUD delivered outside of the OTP setting. Moreover, to measure the complexity of OTP regulations we utilized a simple count of the number of regulations observed in a given state; and the number of regulations 
within different categories. We recognize that future research could improve on this approach by utilizing methods that differentially weigh regulations based on the evidence that underpins them. Finally, we determined whether a type of regulation was considered a best practice based on SAMHSA guidelines that are largely based on expert opinion rather than empirical evidence in many cases. More empirical data on how regulations and best-practice guidelines affect health outcomes is warranted.

As the majority of the most common regulations were not considered best practices, we must consider the possibility that state policies may be creating barriers to access and retention in treatment. Our study lays the foundation for future work to allow for more rigorous evaluations of how OTP regulations affects the establishment, functioning, and performance of OTPs. In addition, our study enables future research to examine the impact of OTP regulations on overdose deaths, the number of patients served, and other population health outcomes. In the meantime, our data can serve as a starting point for discussion among policymakers and experts who can evaluate their own state's regulations and determine which individual regulations might be helpful or harmful in addressing the opioid crisis.

This research did not receive any specific grant from funding agencies in the public, commercial, or not-for-profit sectors. 
Table 1. State-level regulations of opioid treatment programs in effect January 1, 2017 in US states and the District of Columbia (N=51)

\begin{tabular}{|c|c|c|c|}
\hline State Regulations & $\begin{array}{l}\text { \# of states } \\
\text { with this } \\
\text { regulation }\end{array}$ & $\begin{array}{l}\text { Proportion } \\
\text { of states } \\
\text { with this } \\
\text { regulation }\end{array}$ & States with this regulation \\
\hline Medical Services Delivery Requirements Category & $\mathrm{N}=42$ & $82.4 \%$ & \\
\hline Required testing for tuberculosis & 24 & $47.2 \%$ & $\begin{array}{l}\text { AK, AL, AR, CA, CO, GA, IA, IL, IN, ME, } \\
\text { MI, MO, MS, NJ, NM, NY, OH, OK, OR, SC, } \\
\text { TX, WA, WI, WV }\end{array}$ \\
\hline Required reporting of patient deaths & 18 & $35.3 \%$ & $\begin{array}{l}\text { AK, CA, CT, DE, GA, IN, KY, LA, MA, ME, } \\
\text { MI, NY, OK, PA, SC, TX, WA, WI }\end{array}$ \\
\hline Regulations to ensure humane dosage withdrawal schedule & 16 & $31.4 \%$ & $\begin{array}{l}\text { AL, DE, FL, LA, MA, MD, ME, MO, MS, } \\
\text { NH, NJ, OR, RI, SC, TN, VT }\end{array}$ \\
\hline Limits on unsupervised dosing (more restrictive than Federal) & 15 & $29.4 \%$ & $\begin{array}{l}\text { AL, CA, FL, GA, HI, IN, KY, LA, MA, ME, } \\
\text { MI, NH, OH, PA, WI }\end{array}$ \\
\hline Required testing for syphilis & 15 & $29.4 \%$ & $\begin{array}{l}\text { AR, CA, CO, IA, IN, ME, MI, NJ, NM, OH, } \\
\text { OR, RI, SC, TX, WV }\end{array}$ \\
\hline Required lockable container for take-homes (unsupervised dosing) & 14 & $27.5 \%$ & $\begin{array}{l}\text { AK, AL, CO, FL, GA, IN, MA, MD, MO, } \\
\text { MS, OK, TX, WI, WV }\end{array}$ \\
\hline No take-homes in the first 30 days of treatment & 12 & $23.5 \%$ & $\begin{array}{l}\text { AL, CA, CO, FL, KY, LA, MA, ME, MS, } \\
\text { NH, PA, WV }\end{array}$ \\
\hline Required complete blood count testing & 11 & $21.6 \%$ & $\begin{array}{l}\text { AR, CO, GA, IN, MA, MI, NJ, NY, RI, SC, } \\
\text { TX }\end{array}$ \\
\hline Required use of objective measure to test intoxication (e.g. breathalyzer) & 9 & $17.6 \%$ & $\mathrm{AL}, \mathrm{AR}, \mathrm{DC}, \mathrm{KY}, \mathrm{MS}, \mathrm{NC}, \mathrm{NJ}, \mathrm{WI}, \mathrm{WV}$ \\
\hline Mandatory review of patients prescription drug monitoring records & 9 & $17.6 \%$ & $\mathrm{CO}, \mathrm{MA}, \mathrm{MN}, \mathrm{MS}, \mathrm{ND}, \mathrm{NY}, \mathrm{RI}, \mathrm{TN}, \mathrm{WV}$ \\
\hline Restrictions on the use of dose level as a form of punishment & 8 & $15.7 \%$ & GA, KY, MS, ND, RI, SC, WI, WV \\
\hline No unsupervised dosing in the first 90 days of treatment & 7 & $13.7 \%$ & $\mathrm{AL}, \mathrm{CA}, \mathrm{CO}, \mathrm{KY}, \mathrm{ME}, \mathrm{MS}, \mathrm{NH}$ \\
\hline Split dosing explicitly allowed without state approval & 7 & $13.7 \%$ & $\mathrm{AL}, \mathrm{CA}, \mathrm{CO}, \mathrm{ME}, \mathrm{MS}, \mathrm{OK}, \mathrm{WV}$ \\
\hline Restriction or discouragement of high doses & 6 & $11.8 \%$ & $\mathrm{AR}, \mathrm{GA}, \mathrm{IA}, \mathrm{MS}, \mathrm{NC}, \mathrm{WV}$ \\
\hline Required testing for sickle cell disease & 6 & $11.8 \%$ & $\mathrm{AR}, \mathrm{IA}, \mathrm{MI}, \mathrm{MO}, \mathrm{SC}, \mathrm{WV}$ \\
\hline Required testing of liver function & 5 & $9.8 \%$ & CO, MA, ME, RI, TX \\
\hline Use of tablets or diskettes permitted & 5 & $9.8 \%$ & ME, NY, OK, OR, SC \\
\hline Required testing observed collection of all patient urinalysis & 4 & $7.8 \%$ & $\mathrm{AK}, \mathrm{IN}, \mathrm{OR}, \mathrm{WV}$ \\
\hline Restrictions on the use of blind dosing & 4 & $7.8 \%$ & $\mathrm{AK}, \mathrm{CO}, \mathrm{KY}, \mathrm{MA}$ \\
\hline Prohibited unsupervised dosing for patients receiving a high dose & 4 & $7.8 \%$ & $\mathrm{AR}, \mathrm{CA}, \mathrm{IA}, \mathrm{MS}$ \\
\hline Required testing for hepatitis C & 4 & $7.8 \%$ & $\mathrm{MS}, \mathrm{NY}, \mathrm{OK}, \mathrm{WV}$ \\
\hline Regulations on the use of telehealth & 3 & $5.9 \%$ & AZ, NY, OK \\
\hline Regulations on patient dosing wait times & 2 & $3.9 \%$ & $\mathrm{NH}, \mathrm{PA}$ \\
\hline
\end{tabular}




\begin{tabular}{|c|c|c|c|}
\hline Requirement to have naloxone and ability to provide overdose management onsite & 2 & $3.9 \%$ & GA, NY \\
\hline Required testing for hepatitis B & 2 & $3.9 \%$ & MI, MS \\
\hline Discourage or prohibit detoxification during pregnancy & 2 & $3.9 \%$ & $\mathrm{CO}, \mathrm{NJ}$ \\
\hline Administrative Requirements Category & $\mathrm{N}=\mathbf{4 1}$ & $80.4 \%$ & \\
\hline Required facility quality improvement plans & 21 & $41.2 \%$ & $\begin{array}{l}\text { AZ CT, DC, DE, GA, IA, IL, IN, KY, LA, } \\
\text { MD, ME, MN, MO, NM, NY, OH, OK, OR, } \\
\text { TN, WV }\end{array}$ \\
\hline Mandatory use of patient central registry & 20 & $39.2 \%$ & $\begin{array}{l}\text { AL, CA, CO, FL, GA, IA, IN, LA, ME, MN, } \\
\text { MS, NC, NM, NY, OK, RI, TN, TX, VT, WI }\end{array}$ \\
\hline Required patient grievance policy & 19 & $37.3 \%$ & $\begin{array}{l}\text { DE, GA, IN, KY, LA, MA, MD, ME, MO, } \\
\text { NH, NM, OK, OR, PA, RI, TN, TX, VA, WV }\end{array}$ \\
\hline Mandatory community relations liaison/committee & 18 & $35.3 \%$ & $\begin{array}{l}\text { AR, DE, GA, IN, LA, MA, ME, MN, MO, } \\
\text { ND, NH, NM, NY, OK, PA, SC, VA, WA }\end{array}$ \\
\hline Mandatory policies on the use of students and/or interns & 11 & $21.6 \%$ & $\begin{array}{l}\text { AZ, DE, KY, LA, MD, ME, NY, OK, OR, } \\
\text { SD, TX }\end{array}$ \\
\hline Mandatory inclusion of patient photo's in medical record & 7 & $13.7 \%$ & $\mathrm{AL}, \mathrm{CA}, \mathrm{MA}, \mathrm{MS}, \mathrm{PA}, \mathrm{RI}, \mathrm{WA}$ \\
\hline Prohibited policies on kickbacks to patient for new patient referrals & 6 & $11.8 \%$ & AR, GA, KY, MS, ND, NY \\
\hline Restrictions on the use of advertising & 6 & $11.8 \%$ & $\mathrm{AR}, \mathrm{DC}, \mathrm{IA}, \mathrm{LA}, \mathrm{MA}, \mathrm{TX}$ \\
\hline Mandatory patient OTP ID Card & 4 & $7.8 \%$ & $\mathrm{AK}, \mathrm{CA}, \mathrm{DE}, \mathrm{NY}$ \\
\hline Restrictions on the maximum fee per patient & 2 & $3.9 \%$ & IN, TX \\
\hline Required periodic update of patient photo in medical chart & 2 & $3.9 \%$ & PA, WA \\
\hline State set maximum patient capacity & 2 & $3.9 \%$ & $\mathrm{CA}, \mathrm{ME}$ \\
\hline Mandatory algorithm for patient ID \# & 1 & $2.0 \%$ & TX \\
\hline Required affirmative action policy & 1 & $2.0 \%$ & ME \\
\hline Prohibited purses or backpacks in facility & 1 & $2.0 \%$ & MS \\
\hline Staffing Requirements Category & $\mathbf{N}=\mathbf{4 0}$ & $78.4 \%$ & \\
\hline $\begin{array}{l}\text { Regulations on the employment of advanced practice professionals (e.g. nurse } \\
\text { practitioners or physician assistants) }\end{array}$ & 19 & $37.3 \%$ & $\begin{array}{l}\text { AL, CA, CO, CT, DC, DE, FL, GA, IN, LA, } \\
\text { MA, ME, MI, NH, OK, OR, PA, TN, WV }\end{array}$ \\
\hline Required minimum physician or medical director qualifications/certifications & 18 & $35.3 \%$ & $\begin{array}{l}\text { AL, DE, FL, GA, IN, KY, MA, MD, ME, MS, } \\
\text { NJ, NY, OR, PA, TN, TX, VA, WV }\end{array}$ \\
\hline Required counselor to patient ratio's & 17 & $33.3 \%$ & $\begin{array}{l}\text { AL, AR, GA, IN, KY, LA, MD, ME, MS, } \\
\text { NY, PA, SC, TX, UT, WI, WV }\end{array}$ \\
\hline Required employment of a clinical supervisor & 12 & $23.5 \%$ & $\begin{array}{l}\text { AL, CT, IN, KY, LA, MA, ME, NY, OR, TN, } \\
\text { UT, WA }\end{array}$ \\
\hline Required employment of at least 1 CPR certified employee & 11 & $21.6 \%$ & $\begin{array}{l}\text { AZ, DE, GA, KY, MA, ME, ND, SD, TN, } \\
\text { VA, WA }\end{array}$ \\
\hline Required employment of a pharmacist & 9 & $17.6 \%$ & $\mathrm{AL}, \mathrm{CT}, \mathrm{FL}, \mathrm{GA}, \mathrm{IA}, \mathrm{LA}, \mathrm{ME}, \mathrm{MS}, \mathrm{VA}$ \\
\hline Required minimum of clinical supervisor qualifications & 9 & $17.6 \%$ & DE, GA, IN, KY, ME, OK, OR, WA, WV \\
\hline Maximum clinical supervisor caseload & 8 & $15.7 \%$ & DE, GA, IN, ME, OR, UT, WI, WV \\
\hline
\end{tabular}




\begin{tabular}{|c|c|c|c|}
\hline Required employment of a registered nurse & 8 & $15.7 \%$ & IL, LA, MA, MS, NJ, NY, RI, WI \\
\hline Required staff tuberculosis testing & 7 & $13.7 \%$ & DC, IA, IL, MA, MD, TN, WA \\
\hline $\begin{array}{l}\text { Employment restrictions of administrators with history of criminal or unethical } \\
\text { behavior }\end{array}$ & 6 & $11.8 \%$ & KY, LA, ND, NM, TX, WA \\
\hline $\begin{array}{l}\text { Requirement of background checks of all employees/ inability to hire employees } \\
\text { with criminal history }\end{array}$ & 6 & $11.8 \%$ & DC, GA, IA, IL, IN, LA, \\
\hline $\begin{array}{l}\text { Permitted exceptions to minimum qualification of physicians (i.e. interim } \\
\text { physician) }\end{array}$ & 6 & $11.8 \%$ & $\mathrm{MD}, \mathrm{NJ}, \mathrm{NY}, \mathrm{PA}, \mathrm{VA}, \mathrm{WV}$ \\
\hline Required nurse to patient ratio & 6 & $11.8 \%$ & IN, MI, MS, NY, PA, TX \\
\hline Required physician to patient ratio & 6 & $11.8 \%$ & AR, IN, KY, NY, TN, TX \\
\hline Requirements related to the employment of peer professionals & 6 & $11.8 \%$ & DE, IA, LA, NY, OK, VA \\
\hline Prohibited from employing patients & 3 & $5.9 \%$ & FL, OH, OR \\
\hline Restrictions on medical director span of control & 2 & $3.9 \%$ & GA, TN \\
\hline Required employment of a health coordinator required & 1 & $2.0 \%$ & NY \\
\hline Facility Operating Requirements Category & $\mathbf{N}=\mathbf{3 7}$ & $72.5 \%$ & \\
\hline Restrictions on the location of the facility & 22 & $43.1 \%$ & $\begin{array}{l}\text { AL, CT, DC, DE, GA, IA, IL, IN, KY, LA, } \\
\text { ME, MO, ND, NH, NJ, NV, TN, TX, UT, } \\
\text { VA, WI, WV }\end{array}$ \\
\hline Restrictions on the hours of operation & 15 & $29.4 \%$ & $\begin{array}{l}\text { AL, AR, DE, FL, GA, MA, MD, MO, MS, } \\
\text { NC, NH, NY, OK, VA, WI }\end{array}$ \\
\hline Prohibition of patient loitering & 12 & $23.5 \%$ & $\begin{array}{l}\text { AR, GA, IN, MO, MS, NH, NY, OK, SC, TN, } \\
\text { VT, WI }\end{array}$ \\
\hline Required to be open 7 days per week & 11 & $21.6 \%$ & $\begin{array}{l}\text { AL, FL, IN, KY, ME, MS, NH, PA, RI, VA, } \\
\text { WV }\end{array}$ \\
\hline Required certificate of need for new facilities & 10 & $19.6 \%$ & DE, FL, IN, KY, LA, MO, ND, NM, OK, WA \\
\hline Required to be open on holidays & 5 & $9.8 \%$ & AL, FL, ME, MI, MO \\
\hline Social Services Requirements Category & $\mathrm{N}=\mathbf{2 8}$ & $54.9 \%$ & \\
\hline Required patient discharge/aftercare plan & 23 & $45.1 \%$ & $\begin{array}{l}\text { AZ, DC, DE, GA, IN, KY, LA, MA, ME, MI, } \\
\text { MS, ND, NY, OK, OR, PA, RI, SC, SD, TN, } \\
\text { VA, WI, WV }\end{array}$ \\
\hline Mandatory inclusion and integration of patient's family into treatment and goals & 16 & $31.4 \%$ & $\begin{array}{l}\text { AL, AR, DC, DE, IN, LA, ME, MS, NY, OK, } \\
\text { RI, SC, VA, WA, WI, WV }\end{array}$ \\
\hline Required crisis stabilization services & 11 & $21.6 \%$ & $\begin{array}{l}\text { DC, DE, LA, MA, ME, NY, OK, OR, SD, } \\
\text { VA, WI }\end{array}$ \\
\hline Required parenting skills patient education & 10 & $19.6 \%$ & $\begin{array}{l}\text { AL, AR, DE, KY, MA, MS, OR, SC, WA, } \\
\text { WV }\end{array}$ \\
\hline Required life/social skills patient education & 10 & $19.6 \%$ & $\begin{array}{l}\text { AR, DE, KY, LA, MA, ME, MO, OK, OR, } \\
\text { WV }\end{array}$ \\
\hline Required Anger/stress management patient education & 5 & $9.8 \%$ & AR, MA, ME, MS, WV \\
\hline Required family/contraception planning and care & 3 & $5.9 \%$ & CA, MA, WA \\
\hline
\end{tabular}




\begin{tabular}{|l|l|l|l|}
\hline Required to provide voter registration onsite & 1 & $2.0 \%$ & OR \\
\hline Physical Facility Management Requirements Category & $\mathbf{N}=\mathbf{2 8}$ & $\mathbf{5 4 . 9 \%}$ & \\
\hline Requirements on facility cleanliness & 18 & $35.3 \%$ & $\begin{array}{l}\text { CT. DC, DE, IA, KY, LA, MA, ME, MS, ND, } \\
\text { NM, NY, OH, OK, TX, UT, WI, WV }\end{array}$ \\
\hline Restrictions on Restrooms/Lavatory (e.g. \# of restrooms) & 14 & $27.5 \%$ & $\begin{array}{l}\text { CT, DC, DE, GA, IN, KY, MA, ME, MS, OK, } \\
\text { PA, UT, WI, WV }\end{array}$ \\
\hline Guidelines on facility ventilation/lighting & 12 & $23.5 \%$ & $\begin{array}{l}\text { CT, DC, IA, IL, IN, KY, LA, MA, ME, OH, } \\
\text { OR, WI }\end{array}$ \\
\hline $\begin{array}{l}\text { Requirements on facility signage (e.g. no smoking signs or posted hours of } \\
\text { operation) }\end{array}$ & 10 & $19.6 \%$ & AZ, DC, DE, FL, GA, IL, ME, NM, OK, WV \\
\hline Guidelines on waiting room layout or location & 10 & $19.6 \%$ & DE, IN, KY, MA, OH, OK, SC, TX, WI, WV \\
\hline Other facility interior requirements & 9 & $17.6 \%$ & CT, DC, IA, IN, KY, LA, OH, OR, WI \\
\hline Required provision of patient privacy while dosing & 8 & $15.7 \%$ & DE, GA, IN, KY, MI, OH, PA, WI \\
\hline Guidelines on the handling hazardous waste & 6 & $11.8 \%$ & CT, DC, IA, LA, MS, OK \\
\hline Mandatory smoke free facilities and grounds & 6 & $11.8 \%$ & DC, DE, IA, LA, MA, ME \\
\hline Other facility exterior requirements & 5 & $9.8 \%$ & CT, DC, LA, ME, UT \\
\hline Guidelines on facility water and sewage & 5 & $9.8 \%$ & CT, DC, KY, MA, OK \\
\hline Guidelines on facility parking & 3 & $5.9 \%$ & KY, VA, WV \\
\hline Required pest control provisions & 3 & $5.9 \%$ & DC, LA, OK \\
\hline Regulations on the use of carpet/rugs & 1 & $2.0 \%$ & DC \\
\hline Required use of interior/exterior video surveillance & 1 & $2.0 \%$ & MS \\
\hline
\end{tabular}

Source: Laws for inclusion were identified using keyword searches on Westlaw, Justia, and state legislative websites. 
Table 2. Degree to which the most common state-level opioid treatment programs (OTP) regulations are considered best practices by SAMHSA or published studies

\begin{tabular}{|c|c|c|}
\hline Category of OTP Regulation & $\begin{array}{l}\text { Best } \\
\text { Practice? }\end{array}$ & Comments \\
\hline \multicolumn{3}{|l|}{ Medical Services Delivery Requirements } \\
\hline Required testing for tuberculosis & No & $\begin{array}{l}\text { OTPs should provide patients with counseling on HIV and other prevalent infectious diseases, such as } \\
\text { tuberculosis but does not require or suggest testing (Substance Abuse and Mental Health Services } \\
\text { Administration [SAMHSA], 2015). The CDC recommends that providers use tuberculin skin-testing } \\
\text { only if the evaluation and a course of prescribed therapy can be initiated and completed, which is } \\
\text { usually not within the scope of practice for OTPs ("Title 22-A } 6237 \text { DCR } 012056 \text { ", 2015). Thus, the } \\
\text { increased cost of any unnecessary screenings adds to the overall costs of treatment which may } \\
\text { contribute to decreased access and resources. }\end{array}$ \\
\hline $\begin{array}{l}\text { Regulations to ensure humane dosage } \\
\text { withdrawal schedule }\end{array}$ & Yes & $\begin{array}{l}\text { The underlying goal is for involuntary medically supervised withdrawal to reflect a humane partnership } \\
\text { between the patient and the treatment program (SAMHSA, 2015). }\end{array}$ \\
\hline $\begin{array}{l}\text { Limits on unsupervised dosing (e.g., more } \\
\text { restrictive than Federal) }\end{array}$ & No & $\begin{array}{l}\text { SAMHSA acknowledges that take-home medication are a valuable therapeutic tool and program } \\
\text { policies that do not permit take-homes for any patients are ill advised. Take-home medication often are } \\
\text { an element critical for patient retention. SAMHSA recommends that medical directors of OTP's should } \\
\text { ensure that policies for the approval of take-home medication do not create barriers in patient retention } \\
\text { (SAMHSA, 2015). }\end{array}$ \\
\hline Required testing for syphilis & No & $\begin{array}{l}\text { SAMHSA guidelines do not reference syphilis or routine testing. U.S. Prevention services tasked force } \\
\text { recommends syphilis testing for high risk populations, however, individuals in OTPs are not } \\
\text { specifically designated as high-risk, at best, this should be individualized and not a cost incurred by all } \\
\text { patients enrolled. Populations at increased risk based on incidence rates, include individuals who } \\
\text { engage in high-risk sexual behavior, individuals who are HIV positive, and adults in correctional } \\
\text { facilities (Bibbins-Domingo et al., 2016; Cantor, Pappas, Daeges, \& Nelson, 2016). }\end{array}$ \\
\hline $\begin{array}{l}\text { Required lockable container for take-homes } \\
\text { (e.g., for unsupervised dosing) }\end{array}$ & No & $\begin{array}{l}\text { While, SAMHSA guidelines do recommend OTPs ensure patients are aware of the need to secure } \\
\text { medications as with any controlled substance but does not mandate a specific type of locking container. } \\
\text { SAMHSA specifically states that having a specific container presents regulatory challenges such as a } \\
\text { means to identify someone in treatment creating a potential to violate patient confidentiality as well as } \\
\text { put the patient at risk for robbery or assault (SAMHSA, 2015). }\end{array}$ \\
\hline \multicolumn{3}{|l|}{ Administrative Requirements } \\
\hline Required facility quality improvement plans & Yes & $\begin{array}{l}\text { Facilities are required to maintain current quality assurance and control (SAMHSA, 2015). In addition } \\
\text { SAMHSA, recommends continuous quality improvement plans should include: the program's patient } \\
\text { outcome goals; regular and continuous staff education; review and recertification of policies and } \\
\text { procedures (SAMHSA, 2015). }\end{array}$ \\
\hline Mandatory use of patient central registry & No & $\begin{array}{l}\text { Consistent with disaster preparedness, it has been noted that central registries can play an important role } \\
\text { in continuity of care for OTP patients (Elliott, Benoit, Matusow, \& Rosenblum, 2017). However, in the } \\
\text { absence of empirical evidence, SAMHSA only recommends that patients be educated about the } \\
\text { existence of central registries when they are used (SAMHSA, 2015). }\end{array}$ \\
\hline
\end{tabular}




\begin{tabular}{|c|c|c|}
\hline Required patient grievance policy & Yes & $\begin{array}{l}\text { SAMHSA recommends that programs develop and display patient grievance policies to prevent, } \\
\text { investigate, resolve patient complaints, and be responsive to patients' feedback concerning their care } \\
\text { (SAMHSA, 2015). }\end{array}$ \\
\hline $\begin{array}{l}\text { Mandatory community relations } \\
\text { liaison/committee }\end{array}$ & Yes & $\begin{array}{l}\text { SAMHSA recommends that OTPs have policies and procedures to measure and minimize the negative } \\
\text { impact an existing or new program may have on a community (SAMHSA, 2015). }\end{array}$ \\
\hline $\begin{array}{l}\text { Mandatory policies on the use of students and/or } \\
\text { interns }\end{array}$ & No & SAMHSA guidelines do not reference the use of students and/or interns (SAMHSA, 2015). \\
\hline \multicolumn{3}{|l|}{ Staffing Requirements } \\
\hline $\begin{array}{l}\text { Regulations on the employment of advanced } \\
\text { practice professionals (e.g. nurse practitioners or } \\
\text { physician assistants) }\end{array}$ & Yes & $\begin{array}{l}\text { According to SAMHSA guidelines, medication-assisted treatment services may be provided by an } \\
\text { authorized healthcare professional other than a physician such as an advanced practice nurse or } \\
\text { physician assistant testing (SAMHSA, 2015). Many areas of the U.S have an insufficient number of } \\
\text { physicians able or willing to treat substance use disorder with MAT (Sigmon, 2014). Use of advanced } \\
\text { practice professionals may help remove barriers to treatment. }\end{array}$ \\
\hline $\begin{array}{l}\text { Required minimum physician or medical } \\
\text { director qualifications/certifications }\end{array}$ & No & $\begin{array}{l}\text { Guidelines acknowledge that the medical director should have completed an accredited residency } \\
\text { training program and have at least } 1 \text { year of experience in addiction medicine or addiction psychiatry. } \\
\text { However, board certification in addiction psychiatry or addiction medicine is preferred, not required } \\
\text { (SAMHSA, 2015). }\end{array}$ \\
\hline Required counselor to patient ratio's & No & $\begin{array}{l}\text { Federal guidelines state staff ratios should be sufficient to ensure that patients have reasonable and } \\
\text { prompt access to counselors and receive counseling services at the required levels of frequency and } \\
\text { intensity, however, there are no set patient-to-staff ratios specified in SAMHSA guidelines (SAMHSA, } \\
\text { 2015). }\end{array}$ \\
\hline Required employment of a clinical supervisor & Yes & $\begin{array}{l}\text { Research has shown quality clinical supervision may potentially yield important benefits for counselor } \\
\text { well-being (Knudsen, Roman, \& Abraham, 2013). The primary goal of clinical supervision is to protect } \\
\text { the welfare of the client, ensure the integrity of counseling services, and ensure quality counseling care } \\
\text { (CSAT, 2009) }\end{array}$ \\
\hline $\begin{array}{l}\text { Required employment of at least } 1 \mathrm{CPR} \text { certified } \\
\text { employee }\end{array}$ & No & $\begin{array}{l}\text { SAMHSA guidelines do not reference the requirement of one CPR certified employee. OTPs are } \\
\text { advised to operate with full understanding of requirements established by the state or health } \\
\text { professional licensing boards (SAMHSA, 2015). }\end{array}$ \\
\hline \multicolumn{3}{|l|}{ Facility Operating Requirements } \\
\hline Restrictions on the location of the facility & $\begin{array}{l}\text { No } \\
\text { (with caveat) }\end{array}$ & $\begin{array}{l}\text { A significant number of OTP patients travel considerable distances to access treatment. Additionally, } \\
\text { many statess have imposed unfavorable zoning restrictions making access difficult (Des Jarlais, Paone, } \\
\text { Friedman, Peyser, \& Newman, 1995; Peles, Schreiber, \& Adelson, 2013; Rosenblum et al., 2011). } \\
\text { Conflicts between OTP hours and patient work schedules as well as long, complicated public } \\
\text { transportation routes (which can be limited or inaccessible during holidays) have been demonstrated as } \\
\text { a barrier to access and retention (Reisinger et al., 2009). } \\
\text { Caveat: D.C. requires OTPs be placed within access to public transit, which is evidence based } \\
\text { (SAMHSA, 2015). }\end{array}$ \\
\hline Restrictions on the hours of operation & $\begin{array}{l}\text { Yes } \\
\text { (with caveat) }\end{array}$ & $\begin{array}{l}\text { Historically, it was recommended that hours of operation to be scheduled in such a way to minimize } \\
\text { visible congregations of individuals who use illicit substances (Des Jarlais et al., 1995). It was }\end{array}$ \\
\hline
\end{tabular}




\begin{tabular}{|c|c|c|}
\hline & & $\begin{array}{l}\text { acknowledged that odd hours are not always the most convenient for patients and were not typically } \\
\text { conceived to address patient access or retention; but were perceived to promote further stigmatization. } \\
\text { Participants in one study reported OTP clinical routines to be too restrictive and inconvenient, } \\
\text { particularly with regard to the limited operating hours which were often in conflict with patients } \\
\text { working schedules (Wu et al., 2012). Extended OTP operating hours may also help eliminate } \\
\text { overcrowding (CSAT, 2005) SAMHSA recommends that OTPs provide services during hours that meet } \\
\text { the needs of the majority of patients. Most importantly, OTPs should have hours which are outside of } \\
\text { the traditional 8:00 a.m. to 5:00 p.m. schedule (SAMHSA, 2015). } \\
\text { Caveat: State regulations on the hours of operations are highly variable by state, some are within the } \\
\text { guidelines recommendations, and others are broad and may not ensure patients' needs are met. }\end{array}$ \\
\hline Prohibition of patient loitering & No & $\begin{array}{l}\text { A no-loitering policy is believed to help minimize medication diversion (CSAT, 2005). However, } \\
\text { research has pointed out that stigma and bias directed towards OTPs and their patients are the driving } \\
\text { force for these types of regulations (Joseph et al., 2000). Thus, SAMHSA does not consider this as a } \\
\text { best practice. }\end{array}$ \\
\hline Required to be open 7 days per week & No & $\begin{array}{l}\text { Public transportation routes can be limited or inaccessible during holidays have been demonstrated as a } \\
\text { barrier to access and retention (Rosenblum et al., 2011). } \\
\text { A } 2011 \text { study examined commuting patterns among } 23,141 \text { methadone patients and more than half } \\
(60 \%) \text { the patients traveled }<10 \text { miles and } 6 \% \text { travelled between } 50 \text { and } 200 \text { miles (Rosenblum et al., } \\
2011 \text { ). With such a significant number of OTP patients traveling considerable distances to access } \\
\text { treatment, this can become a barrier as a financial burden and physical burden with reduced public } \\
\text { transport during these times. }\end{array}$ \\
\hline Required certificate of need for new facilities & No & SAMHSA guidelines do not reference the need for certificates of need (SAMHSA, 2015). \\
\hline \multicolumn{3}{|l|}{ Social Services Related } \\
\hline Required patient discharge/aftercare plan & Yes & $\begin{array}{l}\text { SAMHSA advises that aftercare planning should begin at admission and include the need for ongoing } \\
\text { management of medical and mental health (SAMHSA, 2015). }\end{array}$ \\
\hline $\begin{array}{l}\text { Mandatory inclusion and integration of patient's } \\
\text { family into treatment and goals }\end{array}$ & Yes & $\begin{array}{l}\text { The involvement of family members contributes to positive treatment outcomes and provides benefits } \\
\text { to the family members (SAMHSA, 2015). This should be completed only with informed consent of the } \\
\text { patient and a signed release of information testing (SAMHSA, 2015). }\end{array}$ \\
\hline Required crisis stabilization services & Yes & $\begin{array}{l}\text { It is recommended, staff should be trained and supported to deescalate physical or verbal threats in the } \\
\text { event that dangerous or threatening situation cannot be deescalated (SAMHSA, 2015). }\end{array}$ \\
\hline Required parenting skills patient education & Yes & $\begin{array}{l}\text { Individuals enrolled in an OTP who are parents, should be provided to education in parenting skills and } \\
\text { child care (SAMHSA, 2015). }\end{array}$ \\
\hline Required life/social skills patient education & No & $\begin{array}{l}\text { With the exception of family involvement, SAMHSA guidelines do not reference the requirement } \\
\text { life/social skills education (SAMHSA, 2015). }\end{array}$ \\
\hline
\end{tabular}




\begin{tabular}{|l|l|l|}
\hline Requirements on facility cleanliness & Yes & SAMHSA recommends OTPs be clean and well maintained (SAMHSA, 2015). \\
\hline $\begin{array}{l}\text { Restrictions on restrooms/Lavatory (e.g. \# of } \\
\text { restrooms) }\end{array}$ & No & $\begin{array}{l}\text { It is recommended by SAMHSA that OTP's consider the physical space, including restrooms, to meet } \\
\text { the needs of female patients (SAMHSA, 2015). However, none of the identified state regulations } \\
\text { pertained to the needs of female patients. }\end{array}$ \\
\hline $\begin{array}{l}\text { Guidelines on facility ventilation/lighting } \\
\text { sequirements on facility signage (e.g. no } \\
\text { smoking signs or posted hours of operation) }\end{array}$ & $\begin{array}{l}\text { No } \\
\text { (with caveat) }\end{array}$ & $\begin{array}{l}\text { SAMHSA does not provide guidelines for facility ventilation and lighting (SAMHSA, 2015). } \\
\text { the OTP's responsibilities and patient rights including patient grievance policies should be posted at } \\
\text { SAMHSA also recommends facility offices and waiting areas should display the names and telephone } \\
\text { number of individuals (e.g., physicians, hospitals, emergency medical technicians) who should be } \\
\text { contacted in case of emergency or utilize 911 or similar local emergency resources (SAMHSA, 2015). } \\
\text { Caveat: 5 of the 10 statess followed best practice guidance. Other states exceed SAMHSA guidelines } \\
\text { and require signage that varied from the best practices. } \\
\text { SAMHSA does not provide guidelines for facility waiting rooms and their location (SAMHSA, 2015). }\end{array}$ \\
\hline Guidelines on waiting room layout or location & No & \multicolumn{2}{|c|}{}
\end{tabular}


Table 3. Relationship between the average number of OTP Regulations, by category, and Select State Characteristics

\begin{tabular}{|c|c|c|c|c|c|c|c|}
\hline \multirow[b]{2}{*}{ State Characteristic } & \multicolumn{7}{|c|}{ Average \# of Regulations ${ }^{1}$} \\
\hline & Total & $\begin{array}{l}\text { Medical } \\
\text { Services } \\
\text { Delivery }\end{array}$ & $\begin{array}{l}\text { Administrative } \\
\text { Requirements }\end{array}$ & $\begin{array}{c}\text { Staffing } \\
\text { Requirements }\end{array}$ & $\begin{array}{c}\text { Facility } \\
\text { Operating } \\
\text { Requirements }\end{array}$ & $\begin{array}{c}\text { Social } \\
\text { Services }\end{array}$ & $\begin{array}{c}\text { Physical } \\
\text { Facility } \\
\text { Management }\end{array}$ \\
\hline \multicolumn{8}{|l|}{ State Size } \\
\hline Small $(\mathrm{N}=15)$ & 11.4 & 3.0 & 1.7 & 2.1 & 1.1 & 1.5 & 1.9 \\
\hline Medium $(\mathrm{N}=25)$ & 17.1 & 4.5 & 2.6 & 3.7 & 1.7 & 2.0 & 2.6 \\
\hline Large $(\mathrm{N}=11)$ & 15.4 & 5.2 & 2.6 & 4.0 & 1.4 & 0.6 & 1.5 \\
\hline$P$-Value & 0.272 & 0.265 & 0.317 & 0.154 & 0.409 & 0.131 & 0.524 \\
\hline \multicolumn{8}{|l|}{ U.S. Census Regions } \\
\hline Northeast $(\mathrm{N}=9)$ & 18.8 & 5.6 & 3.1 & 4.1 & 1.7 & 1.9 & 2.4 \\
\hline Midwest $(\mathrm{N}=12)$ & 11.3 & 3.0 & 1.7 & 2.3 & 1.4 & 0.8 & 3.3 \\
\hline South $(\mathrm{N}=17)$ & 21.8 & 5.5 & 3.2 & 5.0 & 2.3 & 2.5 & 3.3 \\
\hline West $(\mathrm{N}=13)$ & 7.2 & 2.7 & 1.4 & 1.4 & .3077 & 0.8 & 0.61 \\
\hline$P$-Value & $<0.001$ & 0.062 & 0.016 & 0.002 & $<0.001$ & 0.025 & 0.062 \\
\hline \multicolumn{8}{|l|}{ Political Leaning } \\
\hline $55 \%$ or greater voted Republican $(\mathrm{N}=18)$ & 16.1 & 0.7 & 2.3 & 3.3 & 1.8 & 2.0 & 2.2 \\
\hline Other $(\mathrm{N}=21)$ & 14.1 & 0.9 & 2.4 & 3.2 & 1.4 & 1.1 & 1.9 \\
\hline$P$-Value & 0.849 & 0.056 & 0.955 & 0.986 & 0.317 & 0.296 & 0.718 \\
\hline
\end{tabular}

${ }^{1}$ Summated scales were calculated as the sum number of the individual regulations within each category of OTP regulations; as well as the overall number of regulations as reflected in the total column.

Source: Laws for inclusion were identified using keyword searches on Westlaw, Justia, and state legislative websites. Data on the 2016 presidential election was obtained from the Federal Election Commission. Data on 2017 state population estimates and regions was obtained from the U.S Census Bureau. 
Figure 1. Total number of regulations of opioid treatment programs in effect January 1, 2017 in US states and the District of Columbia (N=51)

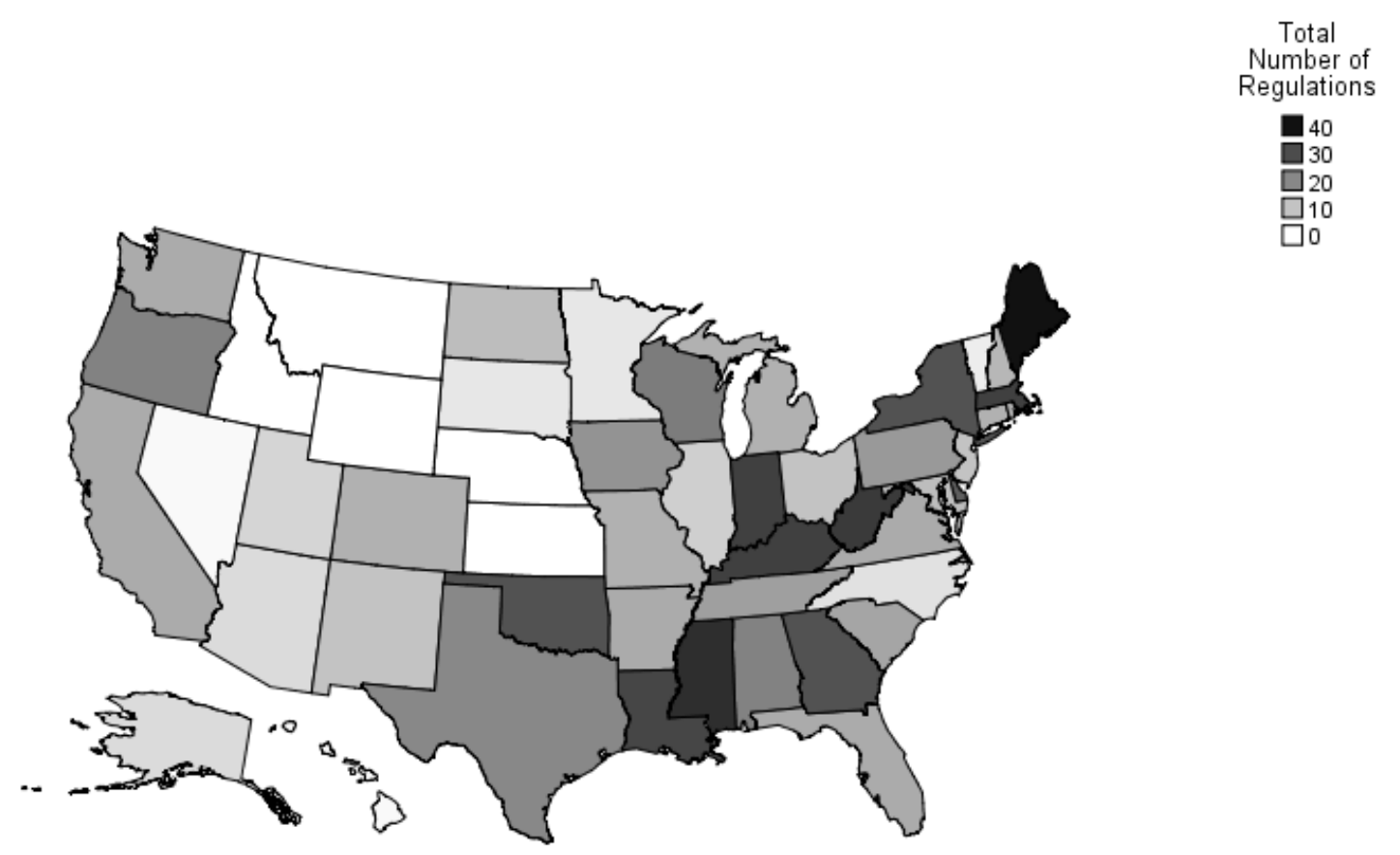

Source: Laws for inclusion were identified using keyword searches on Westlaw, Justia, and state legislative websites. 
Figure 2. Total number of best practice regulations* of opioid treatment programs in effect January 1, 2017 in US states and the District of Columbia $(\mathrm{N}=51)$

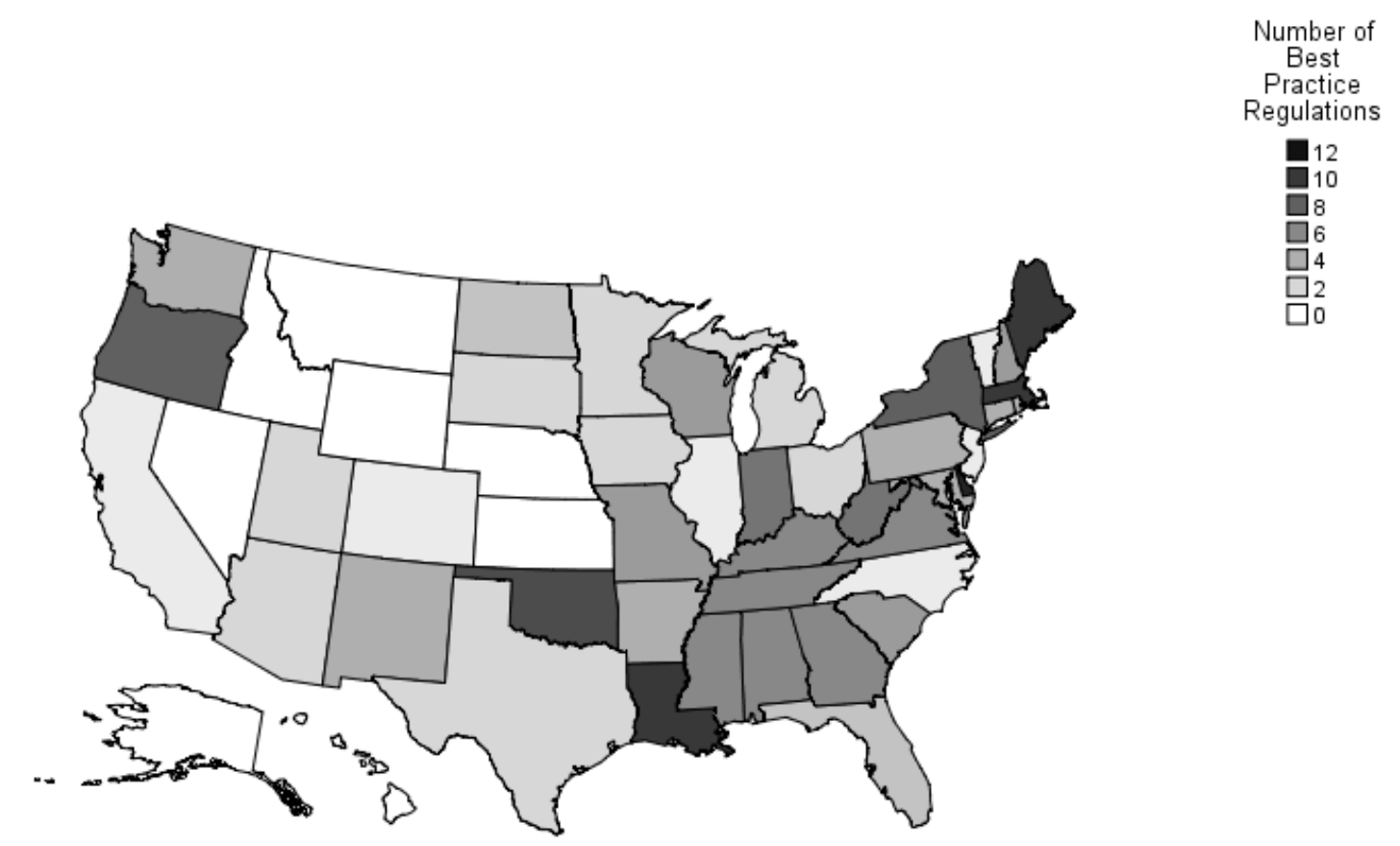

* Best practices were defined by Substance Abuse and Mental Health Services (SAMHSA) guidelines and supporting literature Source: Laws for inclusion were identified using keyword searches on Westlaw, Justia, and state legislative websites. 


\section{References}

Abraham, A. J., Andrews, C. M., Yingling, M. E., \& Shannon, J. (2018). Geographic disparities in availability of opioid use disorder treatment for Medicaid enrollees. Health services research, 53(1), 389-404.

Anderson, E., Tremper, C., Thomas, S., \& Wagenaar, A. (2012). Measuring statutory law and regulations for empirical research.

Anderson, I. B., \& Kearney, T. E. (2000). Medicine Cabinet: Use of methadone. Western Journal of Medicine, 172(1), 43.

Berridge, V. (2009). Heroin prescription and history. The New England journal of medicine, 361(8), $820-1$.

Bibbins-Domingo, K., Grossman, D. C., Curry, S. J., Davidson, K. W., Epling, J. W., García, F. A., Krist, A. H. (2016). Screening for syphilis infection in nonpregnant adults and adolescents: US Preventive Services Task Force recommendation statement. JAMA, 315(21), 2321-2327.

Burris, S. (2018). How to Write a Legal Mapping Paper. Temple University Legal Studies Research Paper(2018-10).

Burris, S., Wagenaar, A. C., Swanson, J., Ibrahim, J. K., Wood, J., \& Mello, M. M. (2010). Making the case for laws that improve health: a framework for public health law research. The milbank quarterly, 88(2), 169-210.

Cantor, A. G., Pappas, M., Daeges, M., \& Nelson, H. D. (2016). Screening for syphilis: updated evidence report and systematic review for the US Preventive Services Task Force. JAMA, $315(21), 2328-2337$. 
Center for Behavioral Health Statistics and Quality. Key substance use and mental health indicators in the United States: Results from the 2015 National Survey on Drug Use and Health.(HHS Publication No. SMA 16-4984, NSDUH Series H-51). 2016.

Center for Substance Abuse Treatment. (2009). Clinical supervision and professional development of the substance abuse counselor.

Center for Substance Abuse Treatment. (2005). Medication-tssisted treatment for opioid addiction in opioid treatment programs. treatment improvement protocol (TIP) Series 43. DHHS Publication No. (SMA) 05-4048. Rockville, MD: Substance Abuse and Mental Health Services Administration.

Centers for Disease Control and Prevention. (1990) Screening for tuberculosis and tuberculous infection in high-risk populations: recommendations of the Advisory Committee for Elimination of Tuberculosis. MMWR Recomm Rep. 39(8):1-7.

Certification of Opioid Treatment Programs, 42 C.F.R Sect 8, (2001).

Certification Standards for Substance Use Disorder Treatment and Recovery Providers, (2017) Chapter A63.6315.24(b).

Chriqui, J. F., Terry-McElrath, Y., McBride, D. C., \& Eidson, S. S. (2008). State policies matter: The case of outpatient drug treatment program practices. Journal of Substance Abuse Treatment, 35(1), 13-21.

Chriqui, J. F., Terry-McElrath, Y., McBride, D. C., Eidson, S. S., \& VanderWaal, C. J. (2007). Does state certification or licensure influence outpatient substance abuse treatment program practices? The journal of behavioral health services \& research, 34(3), 309-328.

Comprehensive Drug Abuse Prevention and Control Act of 1970, Pub. L. No. 91-513(1970). 
Courtwright David, T. (1982). Dark Paradise: Opiate Addiction in America before 1940. Cambridge, MA: Harvard University.

Des Jarlais, D. C., Paone, D., Friedman, S. R., Peyser, N., \& Newman, R. G. (1995). Regulating controversial programs for unpopular people: methadone maintenance and syringe exchange programs. American Journal of Public Health, 85(11), 1577-1584.

Dole, V. P., Nyswander, M. E., \& Warner, A. (1968). Successful treatment of 750 criminal addicts. JAMA, 206(12), 2708-2711.

Elliott, L., Benoit, E., Matusow, H., \& Rosenblum, A. (2017). Disaster preparedness among opioid treatment programs: Policy recommendations from state opioid treatment authorities. International journal of disaster risk reduction, 23, 152-159.

Farrell, M., Ward, J., Mattick, R., Hall, W., Stimson, G. V., Des Jarlais, D., . . Strang, J. (1994). Methadone maintenance treatment in opiate dependence: a review. BMJ: British Medical Journal, 309(6960), 997.

Federal Elections Commission 2016 U.S. Presidential Election Results. Washington, DC 2016. [cited 2019 Mar 5] Available from: https://transition.fec.gov/pubrec/electionresults.shtml

Frimpong, J. A. (2013). Missed opportunities for hepatitis C testing in opioid treatment programs. American Journal of Public Health, 103(6), 1028-1030.

Frimpong, J. A., D’Aunno, T., \& Jiang, L. (2014). Determinants of the availability of hepatitis C testing services in opioid treatment programs: results from a national study. American Journal of Public Health, 104(6), e75-e82.

Gibson, A., Degenhardt, L., Mattick, R. P., Ali, R., White, J., \& O'Brien, S. (2008). Exposure to opioid maintenance treatment reduces long-term mortality. Addiction, 103(3), 462-468. 
Goldstein, A., \& Herrera, J. (1995). Heroin addicts and methadone treatment in Albuquerque: a 22-year follow-up. Drug and Alcohol Dependence, 40(2), 139-150.

Grönbladh, L., Öhlund, L., \& Gunne, L. (1990). Mortality in heroin addiction: impact of methadone treatment. Acta Psychiatrica Scandinavica, 82(3), 223-227.

Hansen, H., \& Roberts, S. K. (2012). Two tiers of biomedicalization: Methadone, buprenorphine, and the racial politics of addiction treatment. In Critical perspectives on addiction (pp. 79-102). Emerald Group Publishing Limited.

Jones, C. M., Campopiano, M., Baldwin, G., \& McCance-Katz, E. (2015). National and state treatment need and capacity for opioid agonist medication-assisted treatment. American Journal of Public Health, 105(8), e55-e63.

Joseph, H., Stancliff, S., \& Langrod, J. (2000). Methadone maintenance treatment (MMT): a review of historical and clinical issues. The Mount Sinai Journal of Medicine, New York, 67(5-6), 347-364.

Kertesz, S. G. (2017). Turning the tide or riptide? The changing opioid epidemic. Substance Abuse, $38(1), 3-8$.

Knudsen, H. K., Roman, P. M., \& Abraham, A. J. (2013). Quality of clinical supervision and counselor emotional exhaustion: The potential mediating roles of organizational and occupational commitment. Journal of Substance Abuse Treatment, 44(5), 528-533.

Kuehn, B. M. (2005). Methadone treatment marks 40 years. JAMA, 294(8), 887-889.

Langendam, M. W., Van Brussel, G., Coutinho, R. A., \& Van Ameijden, E. (2001). The impact of harmreduction-based methadone treatment on mortality among heroin users. American Journal of Public Health, 91(5), 774.

Mattick, R. P., Breen, C., Kimber, J., \& Davoli, M. (2009). Methadone maintenance therapy versus no opioid replacement therapy for opioid dependence. Cochrane Database Syst Rev, 3(3). 
Menzies, D. (1999). Interpretation of repeated tuberculin tests: boosting, conversion, and reversion. American journal of respiratory and critical care medicine, 159(1), 15-21.

Miller, S. M., \& Moulton, S. (2013). Publicness in policy environments: A multilevel analysis of substance abuse treatment services. Journal of Public Administration Research and Theory, $24(3), 553-589$.

Napoli, C., Ferretti, F., Di Ninno, F., Orioli, R., Marani, A., Sarlo, M. G., Orsi, G. B. (2017). Screening for tuberculosis in health care workers: experience in an Italian teaching hospital. BioMed research international, 2017.

Narcotic Addict Treatment Act Pub. L. No. 93-281 (1974).

National Institutes of Health. (2007). NIH Consensus Statement: Effective Medical Treatment of Opiate Addiction.

Netherland J, Hansen H. White opioids: Pharmaceutical race and the war on drugs that wasn't. BioSocieties. 2017;12(2):217-38.

Peles, E., Schreiber, S., \& Adelson, M. (2013). Opiate-dependent patients on a waiting list for methadone maintenance treatment are at high risk for mortality until treatment entry. Journal of Addiction Medicine, 7(3), 177-182.

Prescription Drug Abuse Policy System [cited 2018 May] Available from: http://www.pdaps.org/. Prescription Drug Abuse Policy System. (2018). Retrieved from http://www.pdaps.org/

Reisinger, H. S., Schwartz, R. P., Mitchell, S. G., Peterson, J. A., Kelly, S. M., O'Grady, K. E., Agar, M. H. (2009). Premature discharge from methadone treatment: patient perspectives. Journal of Psychoactive Drugs, 41(3), 285-296. 
Rosenblum, A., Cleland, C. M., Fong, C., Kayman, D. J., Tempalski, B., \& Parrino, M. (2011). Distance traveled and cross-state commuting to opioid treatment programs in the United States. Journal of environmental and public health, 2011.

Savino, D. (2009). Louis D. Brandeis and his role promoting scientific management as a progressive movement. Journal of Management History, 15(1), 38-49.

Sigmon, S. C. (2014). Access to treatment for opioid dependence in rural America: challenges and future directions. JAMA psychiatry, 71(4), 359-360.

Substance Abuse and Mental Health Services Administration Physician and Program Data 2015 [cited 2016 May]. Available from: http://www.samhsa.gov/programs-campaigns/medication-assistedtreatment/physician-program-data.

Substance Abuse and Mental Health Services Administration, National Survey of Substance Abuse Treatment Services (N-SSATS): 2016. Data on Substance Abuse Treatment Facilities. BHSIS Series S-93, HHS Publication No. (SMA) 17-5039. Rockville, MD: Substance Abuse and Mental Health Services Administration, 2017.

Substance Abuse and Mental Health Services Administration. Federal guidelines for opioid treatment programs. Vol HHS Publication No.(SMA) PEP 15-FEDGUIDEOTP. 2015.

Sun, H. M., Li, X. Y., Chow, E. P., Li, T., Xian, Y., Lu, Y. H., ... \& Zhang, L. (2015). Methadone maintenance treatment programme reduces criminal activity and improves social well-being of drug users in China: a systematic review and meta-analysis. BMJ open, 5(1), e005997.

The Comprehensive Drug Abuse Prevention and Control Act Pub. L. No. 91-513, 84, 1236 Stat. (1970).

The Harrison Narcotics Tax Act, Pub. L. No. 63-223 Stat. 785 (3/1/1915, 1914).

Title 42 of the Code of Federal Regulations Part 8, (2001). 
U.S. Department of Health and Human Services, Substance Abuse and Mental Health Services Administration, Center for Behavioral Health Statistics and Quality. 2016 National Survey of Substance Abuse Treatment Services(N-SSATS)Available from: https://datafiles.samhsa.gov/

Wagenaar, A. C., \& Burris, S. (2014). Public health law research: Theory and methods. Journal of Nursing Regulation, 4(4), 60.

Wickersham, M. E., \& Basey, S. (2016). The "Regulatory Fog" of Opioid Treatment. Journal of Public Management \& Social Policy, 22(3), 6.

Wu, F., Peng, C.-Y., Jiang, H., Zhang, R., Zhao, M., Li, J., \& Hser, Y.-I. (2012). Methadone maintenance treatment in China: perceived challenges from the perspectives of service providers and patients. Journal of Public Health, 35(2), 206-212. 